\title{
Axial Spondyloarthritis Flares - Whatever They Are
}

Of the many things that people with ankylosing spondylitis (AS)/axial spondyloarthritis (axSpA) would like the medical profession to achieve for them, among the most pressing is providing effective ways of managing or preventing flares. Flares present a difficult set of problems: They are not predictable and often occur when contact with a physician or physiotherapist is not possible; and in any event, we can neither define nor measure them. And yet they are a major problem that needs to be tackled. Moreover, whatever they are, effective treatment of axSpA ought to prevent them.

In this issue of The Journal, Jacquemin, et $a l^{1}$ have therefore rightly drawn attention to the issue of flares in axSpA and explored frequency and duration in a group of Canadian patients at a time when few were receiving biologic treatment. Although no definition or description of flare was used, they found that most patients admit to having flares with a mean duration of 2 weeks. Indeed, this and other studies $^{2,3,4}$ agree that many people with axSpA consider that flares are very common and sometimes virtually continuous.

So what is a flare? In rheumatoid arthritis (RA), the term flare implies a periodic increase in symptoms, generally associated with an increase in inflammatory activity, evidenced by clinical signs and a rise in the acute-phase response. In RA, flare can be defined numerically according to validated criteria ${ }^{5}$. By analogy, it may be assumed that in axSpA a flare also represents a periodic worsening of symptoms associated with an increase in inflammatory activity. However, objective evidence of the latter is not generally available - especially when spinal symptoms are the issue - and a range of other associated problems may cause people with AS to feel worse. The problematic nature of defining flare in AS is exemplified by Gossec and colleagues $^{6}$, who identified 27 different definitions of the term in axSpA among 38 published studies. No surprise then that Jacquemin, et al did not provide patients with a definition of flare when they asked patients about their experiences of them.

On the one hand, a flare is whatever a patient experiences that might broadly be characterized as a worsening in comfort or well-being. The term implies that what flares up may also flare down, so many interpret this as a transient issue relative to a stable baseline, be that good or bad. Increased inflammation is clearly one important aspect of AS that may be associated with flare, but only one. Worsening symptoms may be due to comorbidities, including peripheral arthritis, enthesitis, uveitis, bowel symptoms due to inflammatory bowel disease, or to unrelated factors such as mechanical back pain, infection (especially in individuals with Crohn disease), an injury, malignancy ${ }^{7}$, or a psychological change that renders symptoms of stable AS harder to bear. All these issues need to be explored in each individual in the analysis of a flare.

On the other hand, a flare indicates that treatment is insufficient either to prevent or to overcome worsening of symptoms. In therapeutic trials flare may be a potentially valuable endpoint signifying either treatment failure ${ }^{8}$ or inability to withdraw or reduce treatment ${ }^{9}$. Thus efforts are being made $^{6}$ to quantify the symptom change that can be interpreted as flare so that this can be built into clinical trials of therapeutic agents. To do so must involve designation of a level of change of either subjective measures such as the Bath Ankylosing Spondylitis Disease Activity Index (BASDAI), objective measures such as C-reactive protein (CRP), or a combination of the 2 - Ankylosing Spondylitis Disease Activity Score (ASDAS) - as representing flare. Such designation must, necessarily, retain an element of arbitrariness. Fortunately, experience with subjective measures and expert physician judgments in AS has turned out to be more reliable than might have been predicted, although axSpA remains dogged by a lack of clear, objective biomarkers of actual inflammatory or osteogenic disease activity.

Hence, in reality, there are 2 flares: one that is ill-defined, endlessly variable, and highly individual; and one that might be strictly measured on a readily applied scale. We must be careful which type of flare we mean when trying to deal with them.

Stone and colleagues described 4 different patterns of

See Patient-reported flares in AS, page 425

Personal non-commercial use only. The Journal of Rheumatology Copyright (C) 2017. All rights reserved. 
flare as fluctuations in symptoms with or without return to the previous baseline ${ }^{3}$, and Brophy and Calin ${ }^{2}$ differentiated between local (1 area) and generalized types of flare. Their patients described the content of flare as pain (100\%), immobility (90\%), fatigue (80\%), and emotional symptoms $(75 \%)$. Cooksey and colleagues 4 identified flares as "severe" or "non-severe" on the basis of the flare pattern described by Stone, et $l^{3}$; severe flares were associated with younger age, higher disease activity between flares, and worse function. Moreover, these individuals also had higher scores for anxiety and depression. Clearly the nature of this link is important for understanding the meaning of flare; severe exacerbations of symptoms may cause psychological symptoms, but psychological symptoms may also influence reporting of symptoms of otherwise stable disease.

It remains unclear whether flares are largely random fluctuations of an unstable disease or specific fluctuations triggered by potentially predictable events. Brophy and Calin's ${ }^{2}$ cohort of patients attributed flares especially to "stress," "overdoing it," and to changes in weather, although injuries and infections were implicated by a minority. Lubrano and colleagues ${ }^{10}$ noted that continuous nonsteroidal antiinflammatory drug intake and raised erythrocyte sedimentation rate were the only predictors of flare, suggesting that active disease may be prone to flares much as surmised by Cooksey, et $\mathrm{al}^{4}$.

From the viewpoint of the clinical trialist, a flare may be seen to represent symptomatic escape from a stable baseline or effective suppressive treatment. This could be an important indicator of treatment efficacy and a valuable measure for clinical trials. For this purpose, an increase of a disease activity measure above a predetermined threshold would seem to be a reasonable indicator of flare. Godfrin-Valnet and colleagues ${ }^{11}$ sought to equate patients' perceptions of their disease using the Patient Acceptable Symptom State ${ }^{12}$ with the BASDAI ${ }^{13}$ and ASDAS (CRP) ${ }^{14}$, as well as physician assessment of flare. They found that scores of BASDAI above 5.2 and ASDAS above 2.3 were associated with perceptions of flare, although they also noted that high scores were also associated with features of depression. In a separate study using the BASDAI, Dougados and colleagues ${ }^{15}$ found that a relative change of $\geq 2$ units or of $\geq 30 \%$ correlated with symptomatic deterioration. In their current Assessment of Spondyloarthritis International Society (ASAS) study, Gossec, et $a l^{6}$ sought a consensus among ASAS members regarding "flare" or "no flare" in a "vignette exercise" leading to a complex range of draft flare definitions that have yet to be validated in further real-life studies.

Clearly, even with such apparent objectivity and simplicity, finding an agreed-upon definition of flare is proving difficult. BASDAI and ASDAS are entirely or largely subjective and acute-phase response measures are clinically helpful but cannot be tied to any gold standard evidence of inflammatory activity. Magnetic resonance imaging clearly has the ability to demonstrate active inflammatory bone and entheseal changes with objectivity. However, current scanning capability may lack the sensitivity needed to explain flares in axial symptoms, and in any event, cost and time would render this an unsuitable flare measure in normal clinical practice. Identifying (a) reliable, quantitative, objective measure(s) of inflammatory activity of AS is arguably the most pressing need in the field of treatment-related axSpA research, but until that nut is cracked, arbitrary and largely subjective measures have to be used. Ultimately, therefore, an index and a threshold that broadly satisfy "expert opinion" will be as good as it gets. Such a flare definition will be flawed, but it is worth remembering that the treatment threshold for biologic treatment (BASDAI score $\geq 4$ ) is also just such a product of subjectivity and expert opinion, but it has served patients reasonably well thus far.

The associations reported between high BASDAI, sensation of flare, and psychological symptoms including anxiety and depression need to be further explored. The relationships will likely be variable and complex but presently, in neither clinical practice nor research, should we presume to understand the full explanation of flare in any individual case without very careful clinical analysis.

So the axSpA flare is a difficult subject in all respects. Perhaps even the term flare, by emphasizing an illusory parallel with RA, has led to unrealistic expectations. But we need a usable pragmatic definition for research, and our patients need suitable robust shorthand to communicate with professionals when they feel worse. In clinical practice, the approach of Jacquemin and colleagues of using a term perfectly defined by the English children's storybook character Humpty Dumpty ${ }^{16}$ ("when I use a word it means just what I choose it to mean - neither more nor less.") seems at least reasonable. There is an urgent need both to develop ways of helping to manage axSpA flares in clinical practice and to devise a widely acceptable definition of axSpA flare. Achieving these 2 goals will likely mean traveling by different, if parallel, paths.

ANDREW C.S. KEAT, ${ }_{M D}$ Department of Rheumatology, Northwick Park Hospital, Harrow, Middlesex HA1 3UJ, UK. Address correspondence to Dr. Keat. E-mail: a.keat@nhs.net

\section{REFERENCES}

1. Jacquemin C, Maksymowych WP, Boonen A, Gossec L. Patient-reported flares in ankylosing spondylitis: a cross-sectional analysis of 234 patients. J Rheumatol 2017;44:425-30.

2. Brophy S, Calin A. Definition of disease flare in ankylosing spondylitis: the patients' perspective. J Rheumatol 2002;29:954-8.

3. Stone MA, Pomeroy E, Keat A, Sengupta R, Hickey S, Dieppe P, et al. Assessment of the impact of flares in ankylosing spondylitis disease activity using the flare illustration. Rheumatology 2008;47:1213-8.

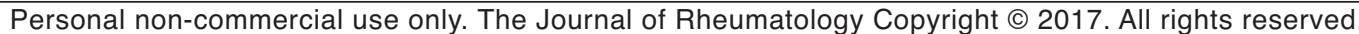


4. Cooksey R, Brophy S, Dennis M, Davies H, Atkinson M, Irvine E, et al. Severe flare as a predictor of poor outcome in ankylosing spondylitis: a cohort study using questionnaire and routine data linkage. Rheumatology 2015;54:1563-72.

5. van der Maas A, Lie E, Christensen R, Choy E, de Man YA, van Riel $\mathrm{P}$, et al. Construct and criterion validity of several proposed DAS28-based rheumatoid arthritis flare criteria: an OMERACT cohort validation study. Ann Rheum Dis 2013;72:1800-5.

6. Gossec L, Portier A, Landewé R, Etcheto A, Navarro-Compán V, Kroon F, et al. Preliminary definitions of 'flare' in axial spondyloarthritis, based on pain, BASDAI and ASDAS-CRP: an ASAS initiative. Ann Rheum Dis 2016;75:991-6.

7. Monti S, Boffini N, Lucioni M, Paulli M, Montecucco C, Caporali R. Spinal non-Hodgkin's lymphoma mimicking a flare of disease in a patient with ankylosing spondylitis treated with anti-TNF agents: case report and review of the literature. Clin Rheumatol 2016;35:275-80.

8. Song IH, Heldmann F, Rudwaleit M, Listing J, Appel H, Haug-Rost I, et al. One-year follow-up of ankylosing spondylitis patients responding to rituximab treatment and re-treated in case of a flare. Ann Rheum Dis 2013;72:305-6.

9. Haibel H, Heldmann F, Braun J, Listing J, Kupper H, Sieper J. Long-term efficacy of adalimumab after drug withdrawal and retreatment in patients with active non-radiographically evident axial spondyloarthritis who experience a flare. Arthritis Rheum 2013;65:2211-3

10. Lubrano E, Massimo Perrotta F, Manara M, D'Angelo S, Addimanda O, Ramonda R, et al. Predictors of loss of remission and disease flares in patients with axial spondyloarthritis receiving antitumor necrosis factor treatment: a retrospective study. J Rheumatol 2016;43:1541-6.

11. Godfrin-Valnet M, Prati C, Puyraveau M, Toussirot E, Letho-Gyselink H, Wendling D. Evaluation of spondylarthritis activity by patients and physicians: ASDAS, BASDAI, PASS, and flares in 200 patients. Joint Bone Spine 2013;80:393-8.

12. Maksymowych WP, Richardson R, Mallon C, van der Heijde D, Boonen A. Evaluation and validation of the patient acceptable symptom state (PASS) in patients with ankylosing spondylitis. Arthritis Rheum 2007;57:133-9.

13. Garrett S, Jenkinson T, Kennedy LG, Whitelock H, Gaisford P, Calin A. BASDAI A new approach to defining disease status in ankylosing spondylitis: the Bath Ankylosing Spondylitis Disease Activity Index. J Rheumatol 1994;21:2286-91.

14. van der Heijde D, Lie E, Kvien TK, Sieper J, Van den Bosch F, Listing J, et al. ASDAS (CRP) ASDAS, a highly discriminatory ASAS-endorsed disease activity score in patients with ankylosing spondylitis. Ann Rheum Dis 2009;68:1811-8.

15. Dougados M, Wood E, Gossec L, van der Heijde D, Logeart I. Flare in axial spondyloarthritis: investigation of meaningful changes in symptomatic outcome measures. Clin Exp Rheumatol 2016; Sep 7 (E-pub ahead of print).

16. Carroll L. Through the looking glass, and what Alice found there. London: Macmillan and Co.; 1872.

J Rheumatol 2017;44:401-3; doi:10.3899/jrheum.170075 